Article

\title{
Narratives of the Refugee Crisis: A Comparative Study of Mainstream-Media and Twitter
}

\author{
Adina Nerghes ${ }^{1}$ and Ju-Sung Lee ${ }^{2, *}$ \\ ${ }^{1}$ Digital Humanities Lab, KNAW Humanities Cluster, 1012DK Amsterdam, The Netherlands; \\ E-Mail: adina.nerghes@dh.huc.knaw.nl \\ 2 Department of Media and Communication, Erasmus University Rotterdam, 3000DR Rotterdam, The Netherlands; \\ E-Mail: lee@eshcc.eur.n \\ * Corresponding author
}

Submitted: 18 January 2019 | Accepted: 7 March 2019 | Published: 28 June 2019

\begin{abstract}
The European refugee crisis received heightened attention at the beginning of September 2015, when images of the drowned child, Aylan Kurdi, surfaced across mainstream and social media. While the flows of displaced persons, especially from the Middle East into Europe, had been ongoing until that date, this event and its coverage sparked a media firestorm. Mainstream-media content plays a major role in shaping discourse about events such as the refugee crisis, while social media's participatory affordances allow for the narratives to be perpetuated, challenged, and injected with new perspectives. In this study, the perspectives and narratives of the refugee crisis from the mainstream news and Twitter-in the days following Aylan's death-are compared and contrasted. Themes are extracted through topic modeling (LDA) and they reveal how news and Twitter converge and also diverge. We show that in the initial stages of a crisis and following the tragic death of Aylan, public discussion on Twitter was highly positive. Unlike the mainstream-media, Twitter offered an alternative and multifaceted narrative, not bound by geo-politics, raising awareness and calling for solidarity and empathy towards those affected. This study demonstrates how mainstream and social media form a new and complementary media space, where narratives are created and transformed.
\end{abstract}

\section{Keywords}

mainstream-media; narratives, networks; refugee crisis; social media; Twitter

Issue

This article is part of the issue "Refugee Crises Disclosed: Intersections between Media, Communication and Forced Migration Processes", edited by Vasiliki Tsagkroni (Leiden University, The Netherlands) and Amanda Alencar (Erasmus University Rotterdam, The Netherlands).

(C) 2019 by the authors; licensee Cogitatio (Lisbon, Portugal). This article is licensed under a Creative Commons Attribution 4.0 International License (CC BY).

\section{Introduction}

In 2015, more than 1.3 million refugees arrived at the borders of the European Union (European Parliament, 2017), with many in need of protection from war, violence, and persecution. The complexity and duration of this influx of displaced individuals have created a climate of uncertainty over the political, economic, and societal implications. In such times of uncertainty, individuals orient themselves towards various types of media (Perse, 2001) in an attempt to understand who the refugees are and what their arrival means for their respective countries. The different media channels used in this search for information (e.g., mainstream-media [MSM] or social media) put forward different affordances and perspectives on the refugee crisis. As perceptions of refugees and migrants have been shown to be rather volatile and easily susceptible when those consuming information feel threatened (Esses, Medianu, \& Lawson, 2013), the type and characteristics of such information are of crucial importance. Consequently, the ways in which refugees are perceived become even more important when considering 
their (social) integration into the societies hosting them. As previous research demonstrates, media coverage contributes greatly to the construction of socially shared understandings and dominant representations of migrants and refugees, which have further consequences on attitudes, sentiments, and even behaviors towards refugees (e.g., Quinsaat, 2014; Robin, 2004; Zembylas, 2010).

In today's complex media environment, MSM outlets-formal news organizations-remain powerful entities, constructing narratives on major events such as the refugee influx into Europe as public issues and/or crises. For instance, as Eberl et al. (2018) show, coverage of immigration is often negative and conflict-centered in European media, with migrants and refugees generally underrepresented and portrayed as delinquents or criminals. Previous studies have also shown that, in an attempt to reduce the complexity of such events, the mainstream mass media use competing frames to create narratives that normalize dominant perspectives on refugees and migrants (Quinsaat, 2014). Two of the most dominant and contrasting frames employed by the MSM in their refugee crisis reporting are those portraying refugees as innocent victims and, simultaneously, as invaders and threats to the physical, economic, and cultural well-being of the respective host country (e.g., Gemi, Ulasiuk, \& Triandafyllidou, 2013).

Since the 9/11 attack on the United States of America, MSM have played an important role in promoting a culture of fear and hostility towards immigrants, refugees, and asylum seekers (Furedi, 2006), portraying refugees as part of plots that threaten our very existence. Such imagery creates a 'fear of the other' and it can be used to achieve political and economic goals (Robin, 2004; Zembylas, 2010).

Refugees are also often portrayed as victims (Harrison, 2016). The picture of the body of toddler Aylan Kurdi's being pulled out of the Mediterranean Sea is just one example of imagery that identifies refugees as victims. The image of Aylan Kurdi, a figure with which the audience might be able to empathize and sympathize, is meant to elicit a feeling of shared humanity (Mamdani, 2010). Sharing personal stories of refugees and victimizing them creates frames that are in direct contrast to the dehumanizing perspective created by the threat and 'fear of the other.'

As Gamson and Modigliani (1989) propose, frames guide comprehension of relevant events and they "work symbolically to meaningfully structure the social world" (Hertog \& McLeod, 2001, p. 140). When creating frames, the media select, emphasize, and exclude actors, events, and issues (Entman, 1993). The narratives created through framing of events can systematically affect how those consuming these narratives come to understand these events (Price, Tewksbury, \& Powers, 1997). Such narratives play a crucial role in the ways crises evolve (Schultz, Kleinnijenhuis, Oegema, Utz, \& van Atteveldt, 2012) and the ways meaning is attributed to a crisis (Van der Meer \& Verhoeven, 2013).
The two examples above-characterizing refugees as threats or as victims-show how the media employ contrasting frames to construct the refugee narrative as national security vs. humanitarian concerns. Such narratives have led to contradictory and inflammatory discourses, with nationalist and racist discourses being countered by liberal-humanitarian discourses (Harrison, 2016). Because the media can empower and disempower governments, citizens, refugees and asylum seekers, such ideological battles and the circulation of polemic imagery can become important aids or obstacles to civic agency and social change (Harrison, 2016).

While in the past MSM channels served as the dominant source of information and the main creators of narratives, with the advent of social media, the public is now able to collaborate in crisis narrative building (Van der Meer \& Verhoeven, 2013). Social media channels have changed the conditions and rules of social interaction (van Dijck \& Poell, 2013), allowing users to challenge media narratives by introducing new/different perspectives into debates (Liu, 2010). Several studies have shown that during crises, people now spend more time online. Especially in the incipient stages of a crisis, when the demand for information transcends what is available, social media users tend to create and disseminate content that significantly differs from that of the MSM (e.g., Liu, 2010). There is a general agreement that debates in social media are not only different from the MSM, but that they also serve omitted or marginalized audiences (Watson, 2016).

\subsection{The Refugee Crisis in Mainstream-Media}

In most societies, the media play a major role in shaping discourses on immigrants and refugees, and the uncertainty and unease their presence evokes (Esses, Brochu, \& Dickson, 2012). Through their reporting, the media construct and promote certain positions on these issues. Such reports on immigrants and refugees have become increasingly negative in the last two decades, with a predominant focus on the threats immigrants and refugees pose to the host societies.

The arrival of refugees on European shores in 2015 has been framed as a crisis, with the refugees themselves being portrayed as different from Europeans, either as vulnerable or as dangerous outsiders. Hate speech and hostility towards migrants and refugees has been systematically and persistently promoted in press coverage, while little attention was paid to the context of the refugees and migrants (Georgiou \& Zaborowski, 2017). This abundance of negative narratives, that ultimately result in the dehumanization of refugees and $\mathrm{mi}-$ grants, may appeal to audiences as they can reinforce the status-quo and strengthen the 'us' versus 'them' boundaries (Leyens, Demoulin, Vaes, Gaunt, \& Paladino, 2007). These types of in-group and out-group divisions can become insurmountable obstacles to civic agency and social change (Harrison, 2016) or even a safety con- 
sideration for the lives and well-being of the refugees and migrants.

\subsection{The Refugee Crisis in Social Media}

While the effects of MSM narratives are not negligible, the dominant narratives they create are, more often than not, both perpetuated and challenged on social media platforms (Siapera, Boudourides, Lenis, \& Suiter, 2018). By allowing users to consume information and also share perspectives on particular events or stories, social media has created a new space of participation in narrative shaping (Papacharissi, 2015). Social media platforms, such as Twitter, also have the potential to reinforce or alter personal opinions (Papacharissi, 2002), be a significant influencer of emotions (Sobkowicz, Kaschesky, \& Bouchard, 2012), and even impact behavior (Walther, DeAndrea, Kim, \& Anthony, 2010).

Although Twitter has been shown to be a primary site for information dissemination during rapidly developing events or fast paced societal crises (e.g., Papacharissi, 2015), studies investigating Twitter debates and user perspectives surrounding the refugee crisis have been slow to emerge. The few studies that do address the topic of the refugee crisis on Twitter expose discourses from solidarity to xenophobic (Gualda \& Rebollo, 2016), emerging frames, elites, and alternative perspectives (Siapera et al., 2018), and a strong dichotomy between the 'deserving' refugee versus the 'undeserving' migrant (Nerghes \& Lee, 2018).

Despite the differing affordances, a complete separation between MSM and social media is no longer realistic. As studies have shown, the sharing and discussing of news between news outlets and Twitter users is a genuine bi-directional exchange, with journalists often quoting tweets and using Twitter as a news-gathering tool, and with many Twitter users sharing and discussing news items (An, Gummadi, Crowcroft, \& Quercia, 2012; Moon \& Hadley, 2014). Thus, Twitter functions as an awareness system for journalists and individuals alike, allowing them to maintain a mental model of news and events (Hermida, 2010).

In the contemporary media environment, MSM and social media actors are involved in a dynamic interplay in which narratives are co-created. In examining the construction of the refugee crisis as a social problem, it is thus essential to investigate the differences and similarities in how the narratives of the crisis are built across these information channels. While such investigations may uncover discussions of alternative perspectives (Milliken \& O'Donnell, 2008), emerging patterns of discursively and socially constructed categorizations of events (Augoustinos, 2001), and marginalizing discourse practices (Fairclough, 2000), not many studies have endeavored to compare narrative building across mainstream and social media. One such study, comparing
Twitter and traditional news content, is that of Zhao et al. (2011). While their study is mostly methodologically oriented, their results reveal patterns of general topic similarity and distinction between the two sources. The study of Van der Meer and Verhoeven (2013) examines framing of organizational crises in news and Twitter and reveals the dynamic characteristics of crisis framing and their potential to prevent crisis escalation. Lastly, Watson (2016) compares the ways in which journalists and Twitter users covered the BP oil spill, and concludes that news and tweets were shaped by similar social and economic factors. When specifically looking at the refugee crisis, and to the best of our knowledge, no previous studies have compared narrative-building across mainstream and social media.

In the present study, we aim to address this lack of research in comparing and contrasting social media and MSM content. Specifically, we explore the construction of the refugee crisis as a social problem by news outlets and Twitter. Employing quantitative text analysis and network analysis, we compare the ways in which Twitter users and MSM shape and magnify different understandings of the refugee crisis, through the emphasis they place on themes portraying refugees. Ultimately, we seek to contribute to the understanding of how the discourse surrounding the refugee crisis has been constructed and the manner by which narratives of the crisis are built across these information channels.

\section{The Case of Aylan Kurdi}

For our analysis, we focus on a high-intensity episode that took place in the incipient stages of the refugee crisis and substantially increased its visibility, namely the tragic death of toddler Aylan Kurdi ${ }^{1}$. The three-year-old Syrian boy of Kurdish ethnic background, who fled the Syrian war-torn town of Kobane with his family and got to Turkey, drowned when the family boarded a small inflatable boat in an attempt to travel from Turkey to the Greek island of Kos (Rayner, 2015). Aylan's body was discovered by locals on the shore of the Akyarlar area of Bodrum, Turkey (Roberts \& Altin, 2015) and later photographed by Turkish journalist Nilüfer Demir.

The images of Aylan's lifeless body have arguably been the most poignant and powerful images to surface in the media at the peak of the Syrian refugee crisis in 2015. The transformative power and iconic potential of Aylan's images have been recognized and emphasized by many, with studies finding that narratives of threat and harm elicited by these images were later related to expressions of solidarity with refugees (Smith, McGarty, \& Thomas, 2018), that the images offered different actors in the refugee debate with new symbols and themes to construct meaning (Bozdag \& Smets, 2017), and that the image of Aylan had value as an agent for social change (De Andrés, Nos Aldas, \& García Matilla, 2016).

\footnotetext{
${ }^{1}$ We note that while the correct spelling of his first name is Alan, both the news and Twitter at the time of his death spelled his name more frequently as Aylan, and so we retain this variant throughout the paper.
} 
While Aylan was by no means the first child to drown en route to Europe (his brother for example being one of the victims of the same accident), nor the last-as Save the Children reported more than 70 children drownings within two months of Aylan's death (Save the Children, 2015)-the image of his body reached the screens of almost 20 million people around the world within 12 hours, generating more than 30,000 tweets (D'Orazio, 2015). The virality of these images shifted popular interest towards the topic of migrants and refugees. As Snow, Vliegenthart, and Corrigall-Brown (2007) demonstrated, when a social event's intensity increases so do the numbers and variations of frames used to characterize such events. Thus, as this tragic event demarcates one of the most intense periods of the refugee crisis, it allows us to examine the incipient stages of narrative building, when audience attention and involvement are heightened (Liu, 2010).

\section{Data and Methods}

Focusing on the period when the tragic death of Aylan Kurdi sparked wide social media engagement to the refugee crisis, we analyze news items from major world publications and tweets published between September 3rd 2015 and September 5th 2015.

For Twitter, 369,485 historical tweets, from 220,710 unique Twitter users, were collected using the ten most popular and relevant hashtags surrounding the refugee/migrant crisis. The following hashtags have been used when collecting our data: \#migrantcrisis, \#migrants, \#migrant, \#refugee, \#refugees, \#refugeecrisis, \#syrianrefugees, \#syrianrefugeesgr, \#refugeeswelcome, and \#muslimrefugees. The data was obtained from historical Twitter data provider Gnip/Sifter and constitute $100 \%$ of the available tweets within our search criteria (similar to the Twitter Firehouse data). Retweets are retained as they are critical in information dissemination and indicate interest in and endorsement of a tweet (Metaxas et al., 2015).

The 1,935 news articles analyzed in this study were obtained from the LexisNexis database by applying a search for the following subjects to all English languages, major world publications: migration issues, immigration, illegal immigration, refugees, displaced persons, and refugee and relief camps. The collection of our news items from all the major world publications was chosen in an attempt to replicate and match the wide and international character of our Twitter corpus. A detailed account of the 89 unique news sources and the number of items collected from each of these sources can be found in the Annex.

The textual content of the newspaper and Twitter data constitutes our corpora. Prior to analysis, the data were cleaned; stop words (aka noise words), numbers, and punctuation were removed, and nouns and verbs were lemmatized and stemmed to their root forms. All words were lower-cased.
Focusing on uncovering and understanding how the narratives of the refugee crisis are constructed across Twitter and MSM, in particular their underlying themes, we employ topic modeling and network analysis.

\subsection{Topic Modeling}

In order to extract the most dominant themes from each corpus, we employ computational topic modeling, specifically latent Dirichlet allocation (LDA), a three-level hierarchical Bayesian model (Blei, Ng, \& Jordan, 2003), as implemented in the 'Ida' R package (Chang, 2015). Topic models are a class of automated text analysis tools that seek to identify, extract, and characterize the various latent topics contained in collections of texts. Individual topics are identified based on word co-occurrence patterns across a corpus of text documents, where a cluster of words that co-occur frequently across a number of documents constitute a topic. Topic models connect words with similar meanings and expose those within distinct themes and differentiate between uses of words with multiple meanings. Each identified topic is separately meaningful and represents a consistent cluster of correlated terms (Blei et al., 2003; Griffiths \& Steyvers, 2004). We also refer to the prominently identified topics as 'themes' when discussing them more qualitatively.

In order to determine the ideal number of topics for our LDA topic modeling, we employ the diagnostic metric proposed by (Deveaud, SanJuan, \& Bellot, 2014), based on which we determined the optimal number of topics for our newspaper data to be 20 and for our Twitter data to be 11 . However, after a qualitative inspection of all the topics generated by the LDA model, we report 18 topics for the newspaper corpus and 11 topics for the Twitter corpus.

We report the top 10 most-relevant words for each topic. Relevant words are computed as

$$
r(w, k \mid \lambda)=\lambda \log \log \left(\phi_{k w}\right)+(1-\lambda) \log \log \left(\frac{\phi_{k w}}{p_{w}}\right)
$$

where $\phi_{k w}$ is a word $w$ proportion within a given topic $k$ and $p_{w}$ is the word's overall proportion in the corpus (Sievert \& Shirley, 2014). A $\lambda=0.4$ yields the best interpretable topics. Finally, we assign a label for each topic based on a qualitative inspection of each topic's words (topic members) and the news articles or tweets strongly associated with the topics. The topic's weight is also reported and it indicates its relative prominence with its respective corpus. Topics are then labeled through qualitative interpretation of their member words and consultation with the source text. Less relevant topics to the refugee crisis can then be identified in this manner.

To further assess the semantic similarity of the topics, we construct a 2-dimensional latent space to position each topic, where their similarities yield positions via an MDS (multidimensional scaling); for the MDS' distance calculation, we use the Jensen-Shannon divergence-a method of measuring the (dis)similarity between two 
probability distributions-on the pairwise topic-word distributions (Fuglede \& Topsoe, 2014). For this, we use the LDAvis R package (Sievert \& Shirley, 2014). Thus, dimensions (and axes) represent the first two principal components that maximize the variance in topic dissimilarities and thus a latent space where similar topics are positioned nearer one another.

\subsection{Topic Networks}

To go beyond the identification of themes constructed in MSM and Twitter, we extend our topic model analysis to include the source of the data. For the news and Twitter data, respectively, the publication (e.g., New York Times) and tweeting usernames (e.g., @Pink) are considered as the sources. Thus, tweets from news source Twitter accounts are included to permit comparison of their positioning via their topics, alongside those of other users. Inclusion of the source results in a 2-mode topic-to-source affiliation matrix or network. These networks represent the association between MSM outlets or Twitter users and the content they generated, in the form of topics. We respectively fold each network, via matrix multiplication, yielding source-to-source networks through which one can identify communities of thematic affiliation. For example, if the New York Times and BBC are strongly connected, we can infer that that these two outlets reported on similar topics and jointly contributed to similar narratives.

To uncover these communities, we use the Newman algorithm. This algorithm assigns nodes into the same group when they appear in dense clusters or subgraphs (Newman, 2006). We distinguish the Newman communities by coloring the nodes in our network visualizations, with each color representing a different community. Furthermore, we identify those MSM outlets and Twitter users that are most vocal-bringing a higher contribution to the creation of narratives - through a measure of volume, of news reporting (number of news items produced) or tweeting (number of tweets produced by each user). These measures are presented by the sizing of the nodes in our network visualizations.

Rather than displaying these networks in their entirety, the interpretation of which would be difficult, we filter them such that only those linkages exhibiting strong topical affiliation (at least 0.7 out 1.0 in the document-totopic matrix) are displayed. For the Twitter network, we further filter the node set by selecting only those nodes whose followers count exceeds the median of 1,526 in order to also examine the embeddedness of such influential users. In each network, we label the top ten nodes to see how these top most prolific sources are embedded in the community network.

\section{Results}

We begin reporting our results with topic modeling, followed by semantic similarity of topics, and the communities of thematic affiliation identified in the networks.

\subsection{Topics in News and Twitter}

In Tables 1 and 2, the topic labels, topic weight, and the top 10 most relevant words are reported. The news' topics paint a more nuanced picture of the themes MSM focused on in the days surrounding the event. Among the prominent topics-those having the highest relative weights-are those focused on ongoing developments: the refugee crisis developing in Europe, general discourse on policy and politics in the context of the crisis, the UK's dealing with the crisis, and events in Hungary, the country through which many refugees endeavored to cross on their way to Western Europe. More specific reporting of the Kurdi family and the virality of the drowned child's images, especially on Twitter, also appear among the top topics. Only one of these topics identified in the news items appear to discuss aid in the context of reports of donations and volunteerism through football clubs. The lower-weighted topics then touch upon issues arising from both the crisis and immigration in other geographic areas and other less relevant themes. Thus, we observe some diversity in the emergent topics, that point to both general and very specific discussions. These results point towards the journalistic process of selecting and prioritizing newsworthy events, where attention to the crisis at large and its political implications supersede the story of Aylan and other stories that could more evoke sympathy or hospitality.

The Twitter topics show similar focus on the overall crisis in Europe and the Kurdi family, as well as developments in Hungary. However, the terminology displays greater specificity than in the news, such as references to the 'March of Hope' film, that documents the refugee plight and journey. Even more specific is the 3rd topic that refers to frequent criticism of UK's Prime Minister David Cameron, comparing his stance on the crisis to that of Finland's Prime Minister Juha Sipilä, who at the time, reportedly, offered his own home to asylum seekers. Interestingly, Twitter users appear to pay more attention to the situation in the Middle East (4th topic), more so than the news, where the topic appears 13th. The prevalent tone in the topics is of both sympathy and optimism, with calls for hospitality (Topic 5), aid, donations, mobilization and activism (Topics 7 and 10), and empathy (i.e., tweets that exhort others to imagine the journey of the refugee, Topic 11). Another fascinating set of tweets draws attention to the fact that the late founder of Apple and "inventor" of the iPhone, Steve Jobs, is a descendant of a Syrian migrant, as a strongly positive framing of migrants and refugees. Thus, we show how the narrative of the refugee crisis in Twitter is transformed beyond the mere factual and informative accounts from MSM into one that can be characterized as stand-taking and activism, designed to raise sympathy and support for refugees. 
Table 1. Topic modeling for the newspaper data.

\begin{tabular}{|c|c|c|c|}
\hline ID & Label & Weight & Topic Members \\
\hline 1 & Refugee Crisis & 0.116 & refugee europe country asylum war people flee million syrians crisis \\
\hline 2 & General Discourse & 0.115 & history political policy world idea prove fact mind wrong hard \\
\hline 3 & United Kingdom & 0.102 & cameron britain uk refugee scheme scotland accept moral crisis leader \\
\hline 4 & Hungarian Border & 0.085 & $\begin{array}{l}\text { station budapest hungary police austria hungarian migrant railway border } \\
\text { camp }\end{array}$ \\
\hline 5 & Kurdi Family & 0.065 & kurdi abdullah boat bodrum brother turkey aylan body capsize rehan \\
\hline 6 & Refugee Quotas & 0.065 & eu orban schengen italy germany quota france migrant slovakia hungary \\
\hline 7 & Travel & 0.056 & hotel book flight shop room festival restaurant museum park driver \\
\hline 8 & Viral Aylan & 0.049 & image child aylan beach shocking dead wash toddler death tweet \\
\hline 9 & Football Club Donations & 0.044 & club donation calais charity football bayern celtic volunteer support raise \\
\hline 10 & Israel-Palestine & 0.039 & $\begin{array}{l}\text { israel idp gaza unicef palestinian israeli displacement borno jerusalem } \\
\text { development }\end{array}$ \\
\hline 11 & China Economy & 0.037 & market china chinese worker investment growth trade investor bank economy \\
\hline 12 & Canada-Kurdi Family & 0.031 & $\begin{array}{l}\text { canada aylan sponsor ottawa toronto sponsorship lifeline trudeau quebec } \\
\text { citizenship }\end{array}$ \\
\hline 13 & Middle East Situation & 0.031 & assad military isil syria iraq arab strike troops islamic militant \\
\hline 14 & UK Politics & 0.031 & corbyn vote labour referendum party election voter key contest candidate \\
\hline 15 & Baltic affairs & 0.030 & russia putin ukraine moscow vladivostok kurdistan report forum kiev rossiya \\
\hline 16 & Australia & 0.030 & australia dutton law fairfax offence citizenship court detention sydney jihad \\
\hline 17 & Nigeria & 0.026 & $\begin{array}{l}\text { customs enforcement corruption defence nigeria suspect lagos arrest } \\
\text { sextortion buhari }\end{array}$ \\
\hline 18 & United States Politics & 0.019 & $\begin{array}{l}\text { trump bush republican clinton american christie mexico reagan presidential } \\
\text { iowa }\end{array}$ \\
\hline
\end{tabular}

\subsection{Similarity of Topics}

Figures 1 and 2 display the MDS layouts of the topics from each corpus, in which similar topics appear closer together. The axes thus represent the first two principal components (PC1 and PC2)-latent dimensions-from the dissimilarity matrix. One distinguishing feature between the two corpora is that the news topics are more widely distributed than the Twitter topics, confirming the divergent attention in the news we observed from the topic labels alone. Still, most of the news topics reside in or near the upper quadrants. The one isolated topic of 'Travel' is unsurprisingly dissimilar as it discusses migration and immigration in the context of travel and tourism. Despite the latent nature of these dimensions, we can qualitatively interpret the horizontal dimension to be an approximate geo-political spectrum of proximity, hence relevance, to the viral event, with the topics of 'Viral Aylan' and 'Kurdi Family' on the far left. Topics linked to direct developments-such as refugees crossing the Hungarian border, the contention that Canada did not receive a bid for asylum from the Kurdi family, the UK's response to the growing crisis-are more closely positioned to the left while secondary topics, that also involve nations geographically less proximal to the crisis, are farther away.

Many of the Twitter topics exhibit considerable overlap in the upper right quadrant of the space, partly due to the overall sympathetic tone of the tweets, in contrast with the neutral reporting found in the news. Still, some topics stand apart. The 'Welcoming Refugees' topic is dominated by tweets with succinct but clear messages of hospitality employing the hashtag \#RefugeesWelcome in retweets such as "Take a stand with us; help make \#RefugeesWelcome" as well as other tweets referring to the Messe Hall in Hamburg that served as a refugee aid center. The 'Call to Action' topic bears some similarity as indicated by its proximity and through its frequent use of \#RefugeesWelcome in tweets such as "\#AylanEurope: no more drownings! \#RefugeesWelcome-Join the global call now!". While the last isolated topic, 'Relating to Refugees', also bears similarity along the horizontal dimension and consequently its solicitous tone, its contents differ by adopting a passive-aggressive tone in 


\section{COGITATIO}

Table 2. Topic modeling for the Twitter data.

\begin{tabular}{|c|c|c|c|}
\hline ID & Label & Weight & Topic Members \\
\hline 1 & Refugee Crisis & 0.154 & europe crisis eu refugeecrisis refugee migrant politics protection smuggle plight \\
\hline 2 & Hungarian Border & 0.125 & $\begin{array}{l}\text { hungary budapest refugee train border marchofhope migrantmarch exodus } \\
\text { bicske police }\end{array}$ \\
\hline 3 & Sipila vs. Cameron & 0.103 & finland home cameron offer house david pm refugee uk sipila \\
\hline 4 & Middle East Situation & 0.097 & middle east syria arab saudi qatar muslim war refugee kuwait \\
\hline 5 & Welcoming Refugees & 0.094 & $\begin{array}{l}\text { stand make refugeeswelcome body hospitality messehallen hamburghilft } \\
\text { stranger angel cloud }\end{array}$ \\
\hline 6 & Kurdi Family & 0.094 & $\begin{array}{l}\text { kurdi father toronto aylankurdi syrianrefugee humanitywashedashore dead } \\
\text { tribute world drown }\end{array}$ \\
\hline 7 & Mobilization of Aid & 0.086 & $\begin{array}{l}\text { donate syrianrefugee human clothes shelter raise kiyiyavuraninsanlik fruit } \\
\text { education organize support }\end{array}$ \\
\hline 8 & Refugee Journey & 0.084 & $\begin{array}{l}\text { germany munich applaud conditions arrive greet westbahnhof refugee hellish } \\
\text { trainofhope }\end{array}$ \\
\hline 9 & Steve Jobs & 0.070 & wealthy steve job iphone invent apple accept man migrant syria \\
\hline 10 & Call to action & 0.048 & global join aylan call drown refugeeswelcome demand propagate europe refugee \\
\hline 11 & Relating to refugees & 0.045 & imagine boat worth missing living life die safe danger family \\
\hline
\end{tabular}

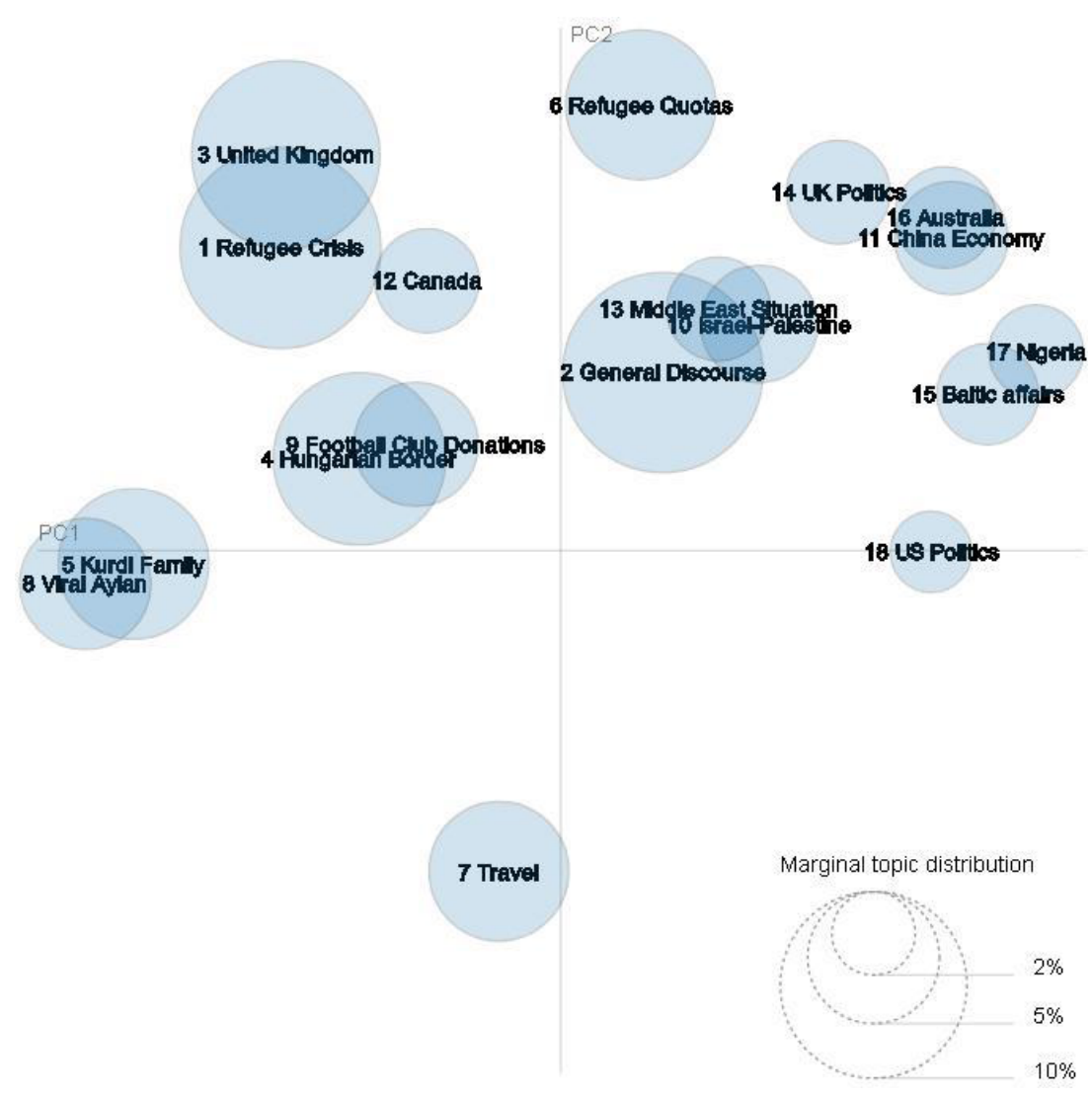

Figure 1. Intertopic distance map (via classical multidimensional scaling) of the newspapers' topics.

its solicitation of sympathy: "If you can't imagine yourself in one of those boats, you have something missing. They are dying for a life worth living." Despite Twitter topics' exhibiting specificity due to use of distinct hash- tags, many are in fact similar to one another-more so than MSM topics-due their consistent sympathetic and activist nature, and less attention to geo-political issues surrounding the crisis. 

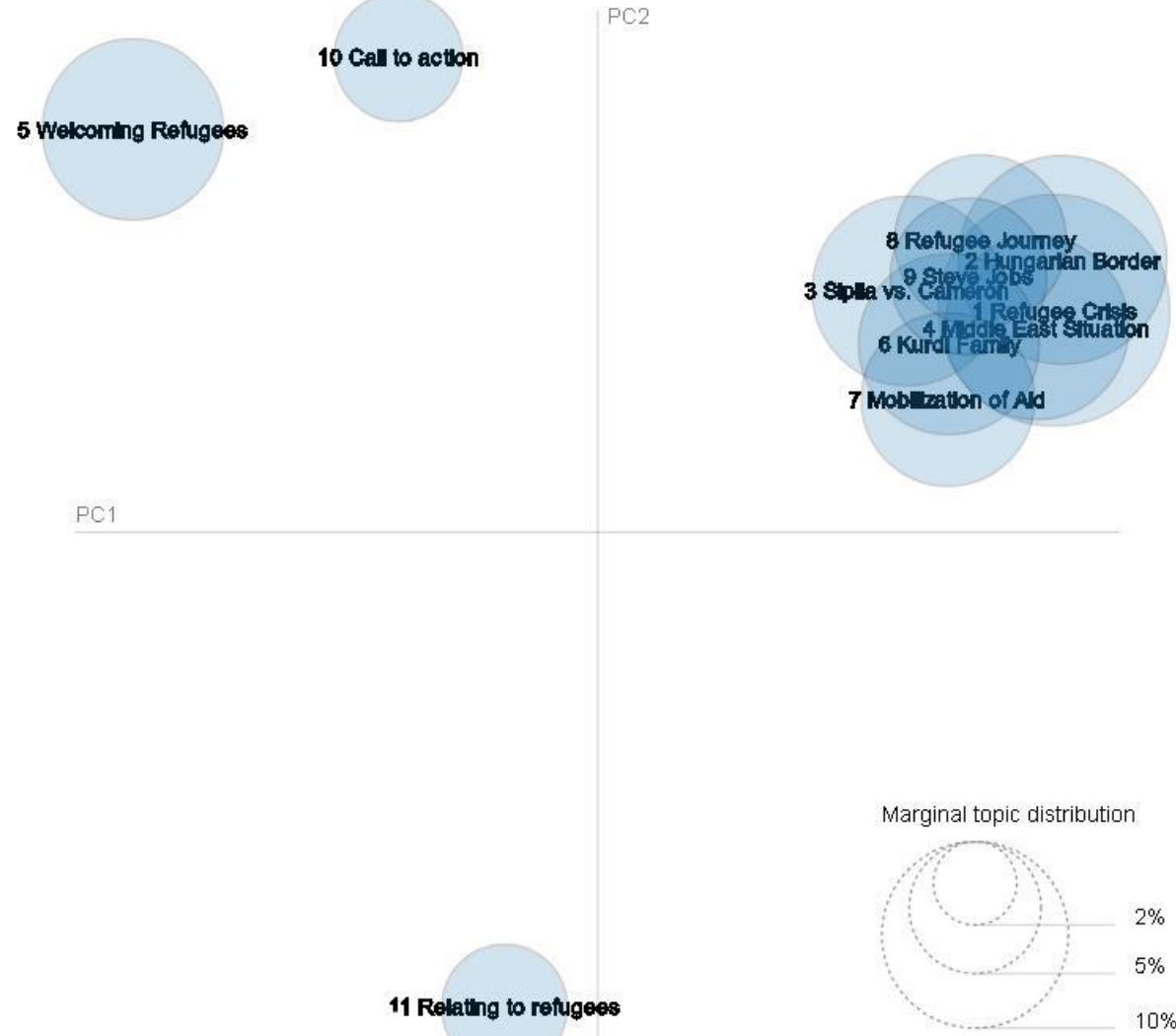

Figure 2. Intertopic distance map (via multidimensional scaling) of the Twitter topics.

\subsection{Communities of Thematic Affiliation}

In Figures 3 and 4, we present networks containing news outlets and Twitter users as nodes and the extent of shared topical contributions as edges.

The news network has two prominent communities of the four detected, the larger one being dominated by UK news outlets. The dominance of UK news in this community reveals a lack of relative diversity in the topics they report. The news outlets of the blue community, of which Africa News and BBC are the most vocal, report on a separate set of topics, namely the 'Nigeria' topic, immigration issues in 'Israel and Palestine' as well as 'Balkan issues', that is also of interest to ITAR-TASS, a Russian news outlet. The yellow community, with nodes unlabeled due to their fewer publications on the crisis, comprise Australian news outlets concerned with the 'Australia' topic as well as those relating to the UK. The New York Times remains apart from these other communities with its focus lying solely on 'United States Politics' and developments at the 'Hungarian Border'. Thus, the geo-political separation implicit in the topic similarities becomes starkly clear through distinct communities in the network depiction: news outlets' attention to the refugee crisis was more regionally focused.

Despite the fewer topics and terseness of tweets compared to news articles, we observe more diversity in how Twitter users are affiliated with topics, with the detection of seven communities. The most prolific and influential users are embedded in two central communities (green and blue) and span international and UK news outlets and accounts of activists and joined by the topics of the overall 'Refugee Crisis', the 'Kurdi Family', and the 'Hungarian Border'. Interestingly, the news outlets on Twitter focus on a smaller subset of topics than in their non-social media publications. The positioning of the other influential users is also revealing. The tweets of celebrities - such as the music artist Pink and authors John Green and J.K. Rowling in the yellow communitylink solely with 'Mobilization of Aid' while bloggers, such as Perez Hilton, tweet on 'Welcoming Refugees' and 'Relating to Refugees'. Fox News reports solely on the general 'Refugee Crisis'. Thus, the presence of activist discourse on Twitter clarifies the homogeneity in the news outlets' topical affiliations. That is, despite the diversity of news topics observed earlier, their lack of focus on exemplars (e.g., the reference to Steve Jobs and the Finnish PM), humanizing perspectives, and sympathy on Twitter confines them to a distinct and restricted narrative space.

\section{Conclusion}

This study investigated how MSM and social media have built narratives on the early developments of the crisis through comparison of emergent narratives, concen- 


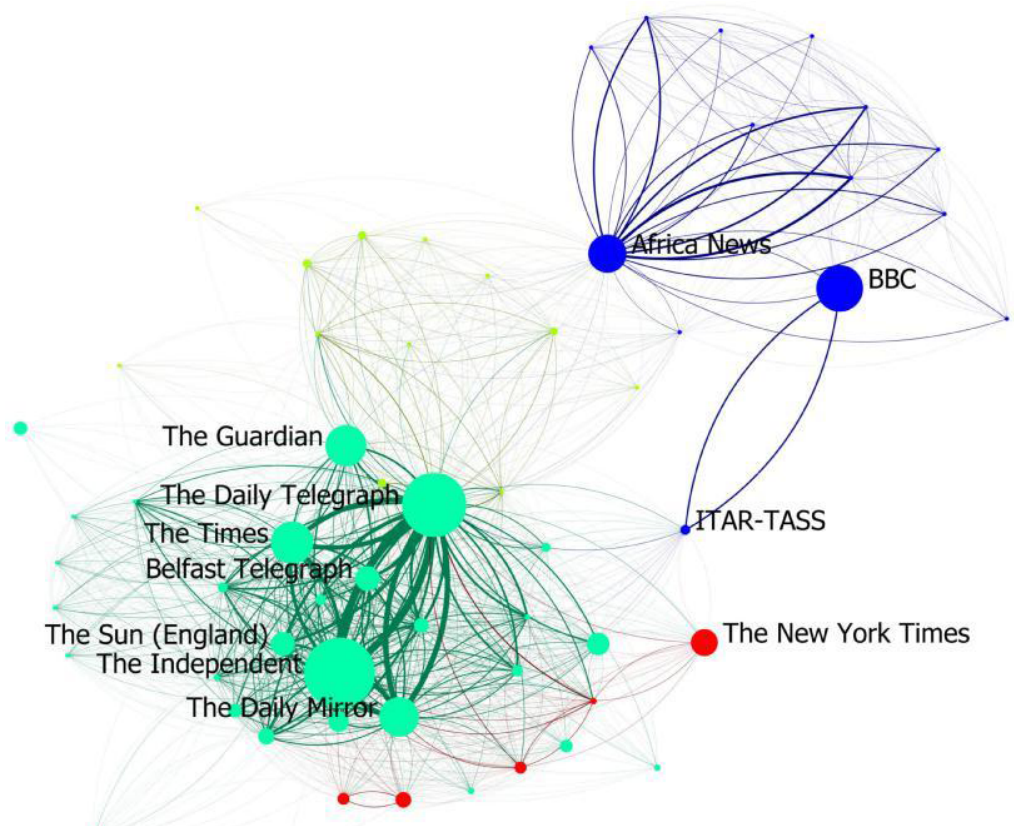

Figure 3. Thematic affiliation network for newspapers ( $N=60,4$ communities).

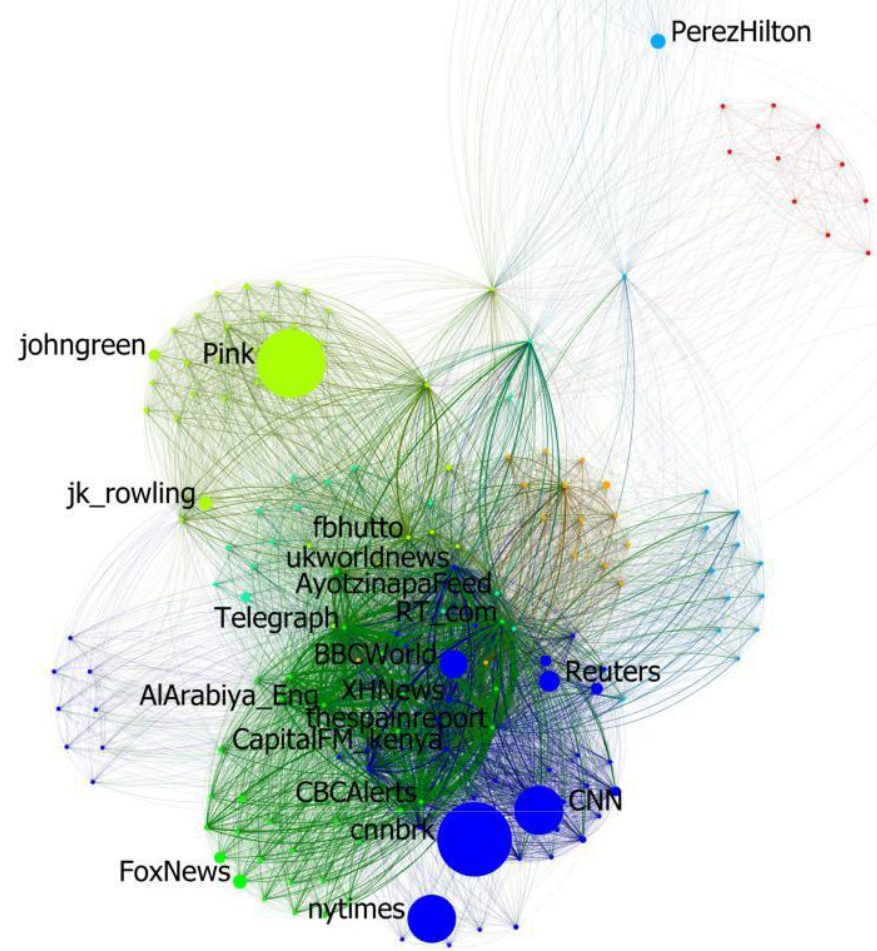

Figure 4. Thematic affiliation network for Twitter ( $N=188,7$ communities). 
trated on the firestorm reaction to the death of Aylan Kurdi. MSM and social media have emerged to become complementary and competing venues through which the public can become informed as well as engage in building narratives, specifically through the participatory affordances of social media and other online venues (Van der Meer \& Verhoeven, 2013).

The distinctions we found between the themes of the two media environments revealed that the two environments are primarily complementary rather than competing. Unlike previous studies, we found evidence of neither competing frames (Quinsaat, 2014) nor the 'us' versus 'them' dichotomies (Leyens et al. 2007) in MSM and Twitter. Rather, we found a neutral and broad discourse in MSM and a focused, highly sympathetic one in social media. While some of the themes on Twitter corresponded to those in the news, Twitter users introduced new themes into the discussion, which should not be surprising since social media afford users with near unlimited opportunities to push debates into new directions (Liu, 2010; Meraz \& Papacharissi, 2013). This distinction remains even though MSM organizations participated in the Twitter discourse. Attention to prominent strands of discussion over the crisis-in public debate and academic research-was fragmented in each environment (Dines, Montagna, Vachelli, 2018). Both MSM and Twitter discussed issues surrounding borders and border control. This commonality can be partly explained by the sharing of news items on Twitter (An et al., 2012; Moon \& Hadley, 2014). However, only MSM politicized the crisis, while Twitter created an alternative narrative of the refugee crisis through solicitations of sympathy and prominent calls-to-action. Thus, news outlets were more geo-politically-oriented in their publications. At the same time on Twitter, these news outlets were topically restricted, and their discussion was disparate from the rest of the Twitter debate.

Most notably, the solicitations of sympathy on Twitter were multifaceted and included placing oneself in the shoes of the refugees, promoting a migrant success story, and exhortation to empowered figures to follow a sympathetic example. Thus, Twitter users contributed to an alternative narrative by calling upon feelings of shared humanity (Harrison, 2016). This humanization and individualization of refugees may empower refugees (KhosraviNik, 2010) and can address uncertainties and anxieties the public experiences (Esses et al., 2013).

The alternative narratives presented on Twitter reflected digital activism, which has been shown to intensify during periods of heightened awareness of a crisis (Mahabir, Croitoru, Crooks, Agouris, \& Stefanidis, 2018). The power of such forms of activism in raising awareness and in placing such issues on political agendas (Yang, 2016)-while at the same time aiding civic agency and social change (Harrison, 2016) - cannot be contested.

Through this study, we contribute to a more nuanced understanding of crisis narrative creation in our current media environment, in which MSM and social media interact in a new participatory media space (Papacharissi, 2015). Showing how the refugee crisis narrative-created by MSM and social mediaconverged and diverged has enabled us to expose emergent perspectives and how they have become dispersed and challenged (Siapera et al., 2018). Most importantly, we show that in the initial stages of a crisis and following the tragic death of Aylan, public sentiment on Twitter was highly positive. Twitter offered an alternative and multifaceted narrative, not bound by geo-politics, to that created by the traditional media. Our study underlines the important role of social media in transforming narratives by creating awareness and calling for solidarity and empathy towards those affected (De Andrés et. al, 2016).

This study was constrained in its scope of three days, to allow for comparison between news and Twitter just when the trigger event occurred. Earlier studies have shown that negative imagery-such as portrayals of refugees as invaders (Gemi et al., 2013) using inflammatory rhetoric (Harrison, 2016)-pervade debates on newcomers. While this was not evident in our analysis, one would expect such discourse to emerge as the uncertainties and implications continued to develop. Thus, future collection and analysis of news coverage and social media content between September 2015 and the present, especially those surrounding the intervening events concerning the crisis, would shed light on the trajectories of news and social media and their evolving thematic focus. Similarly, this study's focus on textual discourse leaves for further study other forms of media that may appear in a tweet, including images and emotionally-charged symbols such as emojis.

Furthermore, as the Twitter data included news organizations in order to observe their topical community embedding alongside that of other users, further study distinguishing the tweets from news and non-news sources would expose a more nuanced comparison. Similar distinctions can be made in comparing the topics and communities between the global news against local/regional news. As for the method of topic modeling, the value of such automated text analytics can be found in the processing of large volumes of data, beyond what is feasible for qualitative analysis, which is capable of uncovering some of the nuance that automated methods may miss. However, 'big data' methods such as topic modeling can still expose linkages in the discourse, despite the variety in language use and semantics (Mohr \& Bogdanov, 2013). Lastly, we note that some of our findings may have been impacted by the different content production rules that govern MSM and social media. While MSM content is produced under specific rules, procedures, and structures-for instance content that is considered sellable (Fuchs, 2010)-social media users can freely create content as individuals (Meraz, 2011).

While MSM coverage of migration issues has been shown to play a significant role in the shaping of public opinion on such issues (Eberl et al., 2018), studies like 
ours contribute towards a more holistic understanding of migration narratives. Such comparative assessments of narrative building in MSM and social media become even more important as anti-immigrant parties rise throughout Europe and open border policies within Europe are increasingly challenged.

\section{Acknowledgments}

We are grateful to the anonymous reviewers whose comments we feel have significantly improved this article. We also thank Dr. Stu Shulman and DiscoverText who graciously awarded us the Twitter data for this study.

\section{Conflict of Interests}

The authors declare no conflict of interests.

\section{References}

An, J., Gummadi, K. P., Crowcroft, J., \& Quercia, D. (2012). Visualizing media bias through Twitter. In Proceedings of the ICWSM (pp. 2-5). Palo Alto, CA: AAAI.

Augoustinos, M. (2001). Social categorization: Towards theoretical integration. In K. Deaux \& G. Philogene (Eds.), Representations of the social (pp. 201-216). Oxford: Blackwell Publishers.

Blei, D. M., Ng, A. Y., \& Jordan, M. I. (2003). Latent dirichlet allocation. Journal of Machine Learning Research, 3, 993-1022.

Bozdag, C., \& Smets, K. (2017). Understanding the images of Alan Kurdi with "small data": A qualitative, comparative analysis of tweets about refugees in Turkey and Flanders (Belgium). International Journal of Communication, 11, 4046-4069.

Chang, J. (2015). Ida: Collapsed Gibbs sampling methods for topic models [Computer software manual]. Retrieved from https://CRAN.R-project.org/package= Ida

D'Orazio, F. (2015). Journey of an image: From a beach in Bodrum to twenty million screens around the world. In F. Vis \& O. Goriunova (Eds.), The iconic image on social media: A rapid research response to the of death of Aylan Kurdi (pp. 11-18). Sheffield: Visual Social Media Lab. Retrieved from https://research.gold.ac.uk/ 14624/1/KURDI\%20REPORT.pdf

De Andrés, S., Nos Aldas, E., \& García Matilla, A. (2016). The transformative image. The power of a photograph for social change: The death of Aylan/La imagen transformadora. El poder de cambio social de una fotografía: La muerte de Aylan. Comunicar, 24(47), 29-37. https://doi.org/10.3916/C472016-03

Deveaud, R., SanJuan, Éric., \& Bellot, P. (2014). Accurate and effective latent concept modeling for ad hoc information retrieval. Document Numérique, 17(1), 61-84. https://doi.org/10.3166/DN.17.1.61-84

Dines, N., Montagna, N., \& Vacchelli, E. (2018). Beyond crisis talk: Interrogating migration and crises in Europe. Sociology, 52(3), 439-447. https://doi.org/10. 1177/0038038518767372

Eberl, J.-M., Meltzer, C. E., Heidenreich, T., Herrero, B., Theorin, N., Lind, F., . . . Strömbäck, J. (2018). The European media discourse on immigration and its effects: A literature review. Annals of the International Communication Association. https://doi.org/ 10.1080/23808985.2018.1497452

Entman, R. M. (1993). Framing: Toward clarification of a fractured paradigm. Journal of Communication, 43(4), 50-58. https://doi.org/10.1111/j.1460-2466. 1993.tb01304.x

Esses, V. M., Brochu, P. M., \& Dickson, K. R. (2012). Economic costs, economic benefits, and attitudes toward immigrants and immigration. Analyses of Social Issues and Public Policy, 12(1), 133-137. https:// doi.org/10.1111/j.1530-2415.2011.01269.x

Esses, V. M., Medianu, S., \& Lawson, A. S. (2013). Uncertainty, threat, and the role of the media in promoting the dehumanization of immigrants and refugees. Journal of Social Issues, 69(3), 518-536. https://doi. org/10.1111/josi.12027

European Parliament. (2017, June 30). EU migrant crisis: Facts and figures. News European Parliament. Retrieved from http://www.europarl.europa.eu/ news/en/headlines/society/20170629ST078630/ eu-migrant-crisis-facts-and-figures

Fairclough, N. (2000). New labour, new language? London: Routledge.

Fuchs, C. (2010). Alternative media as critical media. European Journal of Social Theory, 13(2), 173-192. https://doi.org/10.1177/1368431010362294

Fuglede, B., \& Topsoe, F. (2014). Jensen-Shannon divergence and Hilbert space embedding. In Proceedings of the International Symposium on Information Theory (pp. 1-6). Chicago, IL: IEEE.

Furedi, F. (2006). Culture of fear revisited. London: Continuum.

Gamson, W. A., \& Modigliani, A. (1989). Media discourse and public opinion on nuclear power: A constructionist approach. American Journal of Sociology, 95(1), 1-37. https://doi.org/10.1086/229213

Gemi, E., Ulasiuk, I., \& Triandafyllidou, A. (2013). Migrants and media newsmaking practices. Journalism Practice, 7(3), 266-281. https://doi.org/10.1080/ 17512786.2012.740248

Georgiou, M., \& Zaborowski, R. (2017). Media coverage of the "refugee crisis": A cross-European perspective (Report No. DG1(2017)03). Strasbourg: Council of Europe.

Griffiths, T. L., \& Steyvers, M. (2004). Finding scientific topics. In Proceedings of the National Academy of Sciences, 101(suppl 1), 5228-5235. https://doi.org/ 10.1073/pnas.0307752101

Gualda, E., \& Rebollo, C. (2016). The refugee crisis on Twitter: A diversity of discourses at a European crossroads. Journal of Spatial and Organizational Dynam- 
ics, 4(3), 199-212.

Harrison, A. C. (2016). Mediations of 'the refugee crisis': The (ir)reconciliation of ideological contradictions in fortress Europe. Networking Knowledge, 9(4), 1-18. https://doi.org/10.31165/nk.2016.94.445

Hermida, A. (2010). Twittering the news: The emergence of ambient journalism. Journalism Practice, 4(3), 297-308. https://doi.org/10.1080/ 17512781003640703

Hertog, J. K., \& McLeod, D. M. (2001). A multiperspectival approach to framing analysis: A field guide. In S. D. Reese, O. H. Gandy Jr., \& A. E. Grant (Eds.), Framing public life: Perspectives on media and our understanding of the social world (pp. 136-161). Mahwah, $\mathrm{NJ}$ : Erlbaum.

KhosraviNik, M. (2010). The representation of refugees, asylum seekers and immigrants in British newspapers. Journal of Language and Politics, 9(1), 1-28. https://doi.org/10.1075/jlp.9.1.01kho

Leyens, J.-P., Demoulin, S., Vaes, J., Gaunt, R., \& Paladino, M. P. (2007). Infra-humanization: The wall of group differences. Social Issues and Policy Review, 1(1), 139-172. https://doi.org/10.1111/j.1751-2409. 2007.00006.x

Liu, B. F. (2010). Distinguishing how elite newspapers and A-list blogs cover crises: Insights for managing crises online. Public Relations Review, 36(1), 28-34. https://doi.org/10.1016/j.pubrev.2009.10.006

Mahabir, R., Croitoru, A., Crooks, A., Agouris, P., \& Stefanidis, A. (2018). News coverage, digital activism, and geographical saliency: A case study of refugee camps and volunteered geographical information. PloS One, 13(11), e0206825. https://doi.org/ 10.1371/journal.pone.0206825

Mamdani, M. (2010). Saviours and survivors: Darfur, politics and the war on terror. Lagos: Malthouse Press.

Meraz, S. (2011). Using time series analysis to measure intermedia agenda-setting influence in traditional media and political blog networks. Journalism \& Mass Communication Quarterly, 88(1), 176-194. https://doi.org/10.1177/107769901108800110

Meraz, S., \& Papacharissi, Z. (2013). Networked gatekeeping and networked framing on \#Egypt. The International Journal of Press/Politics, 18(2), 138-166. https://doi.org/10.1177/1940161212474472

Metaxas, P. T., Mustafaraj, E., Wong, K., Zeng, L., O’Keefe, M., \& Finn, S. (2015). What do retweets indicate? Results from user survey and meta-review of research. In Proceedings of the ICWSM (pp. 658-661). Palo Alto, CA: AAAI.

Milliken, M. C., \& O'Donnell, S. (2008). User-generated online video: The next public sphere? In Proceedings of the IEEE international symposium on technology and society (pp. 1-3). Fredericton: IEEE.

Mohr, J. W., \& Bogdanov, P. (2013). Introduction-topic models: What they are and why they matter. Poetics, 41(6), 545-569. https://doi.org/10.1016/j.poetic. 2013.10.001
Moon, S. J., \& Hadley, P. (2014). Routinizing a new technology in the newsroom: Twitter as a news source in mainstream media. Journal of Broadcasting and Electronic Media, 58(2), 289-305. https://doi.org/10. 1080/08838151.2014.906435

Nerghes, A., \& Lee, J.-S. (2018). The refugee/migrant crisis dichotomy on Twitter: A network and sentiment perspective. In Proceedings of the ACM conference on web science (pp. 271-280). Amsterdam: ACM.

Newman, M. E. J. (2006). Modularity and community structure in networks. Proceedings of the National Academy of Sciences, 103(23), 8577-8582. https:// doi.org/10.1073/pnas.0601602103

Papacharissi, Z. (2002). The virtual sphere: The internet as a public sphere. New Media \& Society, 4(1), 9-27. https://doi.org/10.1177/14614440222226244

Papacharissi, Z. (2015). Toward new journalism(s): Affective news, hybridity, and liminal spaces. Journalism Studies, 16(1), 27-40. https://doi.org/10.1080/ 1461670X.2014.890328

Perse, E. M. (2001). Media effects and society. London: Routledge.

Price, V., Tewksbury, D., \& Powers, E. (1997). Switching trains of thought: The impact of news frames on readers' cognitive responses. Communication Research, 24(5), 481-506. https://doi.org/10.1177/ 009365097024005002

Quinsaat, S. (2014). Competing news frames and hegemonic discourses in the construction of contemporary immigration and immigrants in the United States. Mass Communication and Society, 17(4), 573-596. https://doi.org/10.1080/15205436.2013.816742

Rayner, G. (2015, September 3). Aylan and Galip Kurdi: Everything we know about drowned Syrian refugee boys. The Telegraph. Retrieved from https://www.telegraph.co.uk/news/worldnews/ europe/11841802/eu-migrant-crisis-refugee-boysaylan-galip-kurdi.html

Roberts, H., \& Altin, V. (2015, September 3). 'Their eyes were open. I closed them softly': Turkish barman who found body of toddler Aylan Kurdi on beach relives his horror. Mail Online. Retrieved from https:// www.dailymail.co.uk/news/article-3220992/Theireyes-open-closed-softly-Turkish-barman-bodytoddler-Aylan-Kurdi-beach-relives-horror.html

Robin, C. (2004). Fear: The history of a political idea. Oxford: Oxford University Press.

Save the Children. (2015). More than 70 children have drowned trying to get to Greece since Aylan Kurdi. Save the Children. Retrieved from https:// www.savethechildren.net/article/more-70-childrenhave-drowned-trying-get-greece-aylan-kurdi

Schultz, F., Kleinnijenhuis, J., Oegema, D., Utz, S., \& van Atteveldt, W. (2012). Strategic framing in the BP crisis: A semantic network analysis of associative frames. Public Relations Review, 38(1), 97-107. https://doi. org/10.1016/j.pubrev.2011.08.003

Siapera, E., Boudourides, M., Lenis, S., \& Suiter, J. (2018). 
Refugees and network publics on Twitter: Networked framing, affect, and capture. Social Media + Society, 4(1). https://doi.org/10.1177/2056305118764437

Sievert, C., \& Shirley, K. (2014). LDAvis: A method for visualizing and interpreting topics. In Proceedings of the workshop on interactive language learning, visualization, and interfaces (pp. 63-70). Baltimore, ML: ACL.

Smith, L. G. E., McGarty, C., \& Thomas, E. F. (2018). After Aylan Kurdi: How tweeting about death, threat, and harm predict increased expressions of solidarity with refugees over time. Psychological Science, 29(4), 623-634. https://doi.org/10.1177/ 0956797617741107

Snow, D. A., Vliegenthart, R., \& Corrigall-Brown, C. (2007). Framing the French riots: A comparative study of frame variation. Social Forces, 86(2), 385-415. https://doi.org/10.1093/sf/86.2.385

Sobkowicz, P., Kaschesky, M., \& Bouchard, G. (2012). Opinion mining in social media: Modeling, simulating, and forecasting political opinions in the web. Government Information Quarterly, 29(4), 470-479. https:// doi.org/10.1016/j.giq.2012.06.005

van der Meer, T. G. L. A., \& Verhoeven, P. (2013). Public framing organizational crisis situations: Social media versus news media. Public Relations Review, 39(3), 229-231. https://doi.org/10.1016/j.pubrev.2012.12. 001 van Dijck, J., \& Poell, T. (2013). Understanding social media logic. Media and Communication, 1(1), 2-14. https://doi.org/10.12924/mac2013.01010002

Walther, J. B., DeAndrea, D., Kim, J., \& Anthony, J. C. (2010). The influence of online comments on perceptions of antimarijuana public service announcements on YouTube. Human Communication Research, 36(4), 469-492. https://doi.org/10.1111/ j.1468-2958.2010.01384.x

Watson, B. R. (2016). Is Twitter an alternative medium? Comparing Gulf coast Twitter and newspaper coverage of the 2010 BP oil spill. Communication Research, 43(5), 647-671. https://doi.org/10.1177/ 0093650214565896

Yang, G. (2016). Narrative agency in hashtag activism: The case of \#BlackLivesMatter. Media and Communication, 4(4), 13-17. https://doi.org/10.17645/mac. v4i4.692

Zembylas, M. (2010). Agamben's theory of biopower and immigrants/refugees/asylum seekers. Discourses of citizenship and the implications for curriculum theorizing. Journal of Curriculum Theorizing, 26(2), 31-45.

Zhao, W. X., Jiang, J., Weng, J., He, J., Lim, E.-P., Yan, H., \& Li, X. (2011). Comparing Twitter and traditional media using topic models. In Proceedings of the European conference on IR research (pp. 338-349). Dublin: Springer Verlag.

\section{About the Authors}

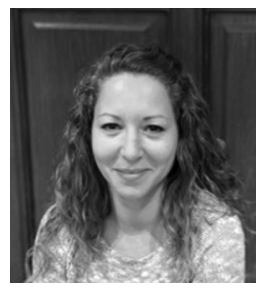

Adina Nerghes (PhD, Vrije Universiteit Amsterdam) is a Postdoctoral Researcher in the Digital Humanities Lab at the KNAW Humanities Cluster. Her research focuses on language use in various social contexts and emerging social structures. She has investigated the refugee crisis debates in social media, strategies of health consumers and their interactions in the social media space, and discourses of newspapers, central banks, and the European Parliament.

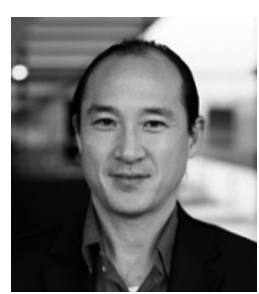

Ju-Sung (Jay) Lee (PhD, Carnegie Mellon University) is an Assistant Professor in the Department of Media and Communication at Erasmus University Rotterdam. His research focuses on structures found in society and the texts it produces, particularly social media. His work has explored social, communication, and semantic networks in a variety of contexts including the refugee crisis, the financial crisis, artist communities, and teenage substance use. 
Annex

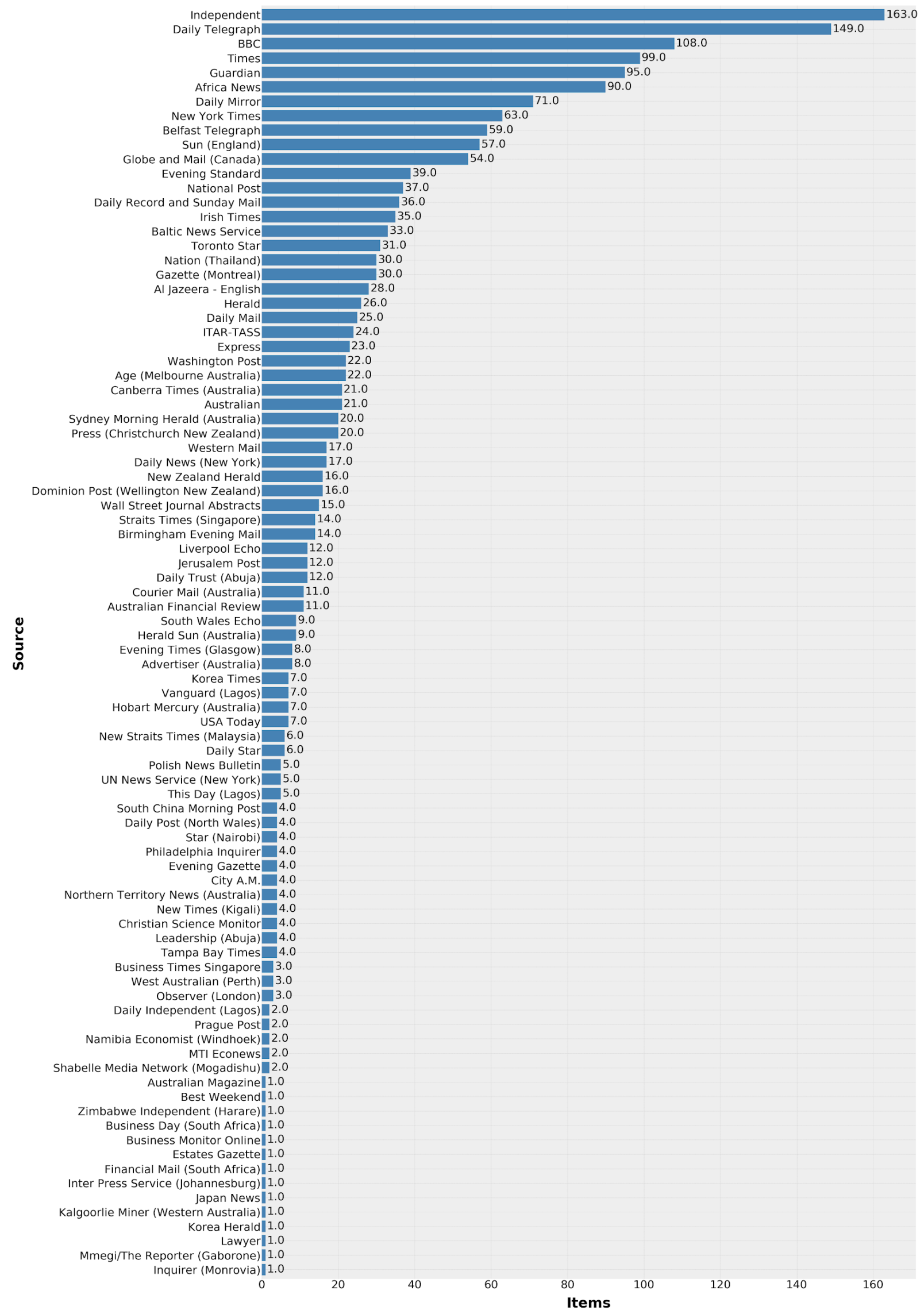

Figure 1A. News outlets and the number of items collected. 